\title{
THE BRITISH FLORA IN 1957
}

\begin{abstract}
$\mathrm{T}$ HE investigation of the British flora has passed through many phases. The pest decade has been characterized mainly by concentration on detailed studies of individual species, or of small groups, making full use of the techniques of ecology, genetics and cytology as aids to taxonomy. In addition, there has been the detailed study of distribution organized by the Distribution Maps Scheme of the Botenical Society of the British Isles which has received the support of more than three thousand helpers. As a result of all this research, it has become more evident each year that the flora of the British Isles cannot be satisfactorily studied in isolation; it must be considered in relation to the European flora of which it forms a part. There has been an increasing tendency for British workers to make better use of Continental research, and to trevel abroad to study the behaviour of British species overseas. It seems likely that this attitude will become the outstanding feature of the next phase of the study of the British flora, and that with the increased facilities of modern travel any remaining insularity will diseppear.
\end{abstract}

It was in the belief that we are on the threshold of a change in emphasis, that exhibits on the relationship of the British to the European flora were a special feature of the Annual Exhibition Meeting of the Botanical Society of the British Isles on Novem. ber 30. This was arranged in the lecture hall of the British Museum (Natural History), by kind permission of the Trustees, and was attended by 360 members and guests. There were fifty-nine exhibits.

The exhibit prepared by Prof. T. G. Tutin (Leicester) under the title of "Some Straightforward British Plants and their Continentel Complexities" showed Ranunculus bulbosus, Primula elatior and Helleborus viridis. In Britain these provide no taxonomic difficulties, but the buttercup, characterized here by the swollen stem tuber, produces only a feebly developed bulb in the south of France, and no bulb at all in Spanish and Italian specimens; while the other two species exhibit subspecific variation in Europe with differences in habitat, distribution and morphology. Prof. D. A. Webb (Dublin) showed examples from the Irish flora of species which can only be understood by studying their behaviour in Spain. Thus, in Ireland, Saxifraga hirsuta hybridizes so freely with $S$. spathularis that it is very difficult to find the pure species; but in Spain the two are separated geographically, and much better differentiated ecologically. In Ireland, Erica mackaiana is sterile, producing only about one viable soed for every thousand flowers, but in Spain it sets seod freely but is self-sterile. It seems that both the Galway and Donegal populations may consist of a single clone.

Progress and problems of the projected "Flora Europæe"1, which is expected to include descriptions of some 16,000-17,000 kinds of plents, were illustrated by Dr. V. H. Heywood (Liverpool). As examples of the difficulties of producing a condensed account of complex groups on modern lines, he showed series of Anthyllis vulneraria, and the clines in Pinus nigra aggr. Both have been the subject of voluminous literature; of the former, Jalas has published a recent treatment of part of the complex based largely on field and herbarium material ; on the latter, ten papers on nomenclature have appeared during the past twenty-five years, but both require much work to produce suitable treatments over the whole area covered. The compilers of the "Flora Europae" have many similar problems to face. Among the other exhibits which considered British plants in relation to their distribution or variation elsewhere were those provided by Dr. D. E. Coombe (Cambridge) on Carex humilis, N. K. B. Robson (Kew) on Hypericum maculatum, J. P. Savidge (Liverpool) on Callitriche, Dr. S. M. Walters (Cambridge) on Carex section Distantes, and Dr. E. F. Warburg (Oxford) on Sorbus. Fresh flowers and fruits from the Riviera were shown by Miss M. S. Campbell.

During 1957 there have been no important species added to the British list, but several very rare ones have been found in new localities. The most interesting of these is Spiranthes romanzoffiana, which was found in July on Dartmoor, and was exhibited by P. C. Hall and Mrs. B. Welch. This orchid was not previously known from England, and in some respects the Dartmoor plant is intermediate between the populations found in southern Ireland and those in northern Ireland and Scotland. R. A. Graham and R. M. Harley exhibited Mentha $\times$ piperita var. sylvestris from near Brixham, collected by $\mathbf{K}$. Bull in 1954 , as a mint not soen for 150 years. It was originally collected near Bath about 1790. Poa bulbosa was shown by J. Hodgson from near Frensham, Surrey. It is the first record of this usually maritime gress from the county since 1762 , but although the new habitat is a suitable one, association with other species known to have been intro. duced suggests that the plant is not native here.

Considerable attention is now being devoted to the study of hybrids in the British flora. The old reproach, that if a plant proved difficult to name the easy way out was to call it a hybrid, is no longer true, and botanists are now investigating claims to hybridity with painstaking care. The British Museum (Natural History) exhibited type specimens of two hybrids new to science-Potamogeton $\times$ cadburyae, which is a cross between $P$. crispus and $P$. lucens, and $P$. $\times$ pseudofriesii, which is a cross between $P$. acutifolius and $P$. friesii. Both were described by J. E. Dandy and G. Taylor. An interesting example of a hybrid detected in the field was Symphytum peregrinum $\times$ tuberosum shown from Woodbridge, Suffolk, by E. Milne-Redhead (Kow). Synthetic hybrids in Spergularia were shown by J. A. Ratter (Liverpool). By artificial cross-pollination he produced $S$. bocconi $\times$ salina and $S$. salina $\times$ rupicola-in both there was complete failure to produce fruit, and flowering continued throughout the season. Dr. B. A. Hulme showed artificially produced hybrids in Atriplex. Using $A$. patula, $2 n=36, A$. hastata, $2 n=18$, and A. littoralis, $2 n=18$, as parents, she found that there was free crossing between $A$. patula and $A$. littoralis, but not between $A$. patula and $A$. hastata, and she was unable to produce $A$. hastata $\times$ littoralis. 
P. M. Benoit had four exhibits of hybrids. Festuca rubra $\times$ Vulpia myuros was claimed as new to science. A single plant was found in Merioneth, morphologically intermediate, and completely sterile. Cardamine flexuosa $\times$ hirsuta he had synthesized, making successful crosses in both directions. Myosotis caespitosa $\times$ scorpoides he found in a marshy meadow at Dolgelley in 1956--this is new to the British Isles. He also had a very convincing exhibit of the common hybrid Senecio aquaticus $\times$ jacobaea, which is partially fertile and very variable and forms complex hybrid swarms. Dr. S. M. Walters and Miss A. Martin (Cambridge) showed an interesting study of Calystegia sepium and $C$. sylvestris. This was based on five populations in and near Cambridge for which they had scored measurements of parts of the flowers and arranged them on the principle of Anderson's "Hybrid Index". Both species are markedly incompatible, and small populations usually arise from a single clone and therefore set little or no seed, but seed is set in larger populations or those which are heterogeneous. Their analysis showed that morphologically intermediate populations of presumed hybrid origin occur frequently in the vicinity of Cambridge and presumably arose by cross-fertilization.

Two exhibits directed attention to new techniques. B. E. Juniper (Oxford) showed replicas of leaf surfaces obtained by the use of the electron microscope. These included, for example, Oxalis corniculata var. atropurpurea under a magnification of 34,000 linear. When the investigation of structures beyond the resolution of the light microscope is more advanced, new characters may be revealed to assist the work of taxonomists. D. E. Bradley exhibited a series of flowers of native orchids preserved by an embedding technique. After treatment in a colour-preserving solution, they were dried and embedded in transparent blocks of cold-setting 'Ceemar' resin.

Other aspects of British botany were represented by further exhibits, but it was clear that the Distribution Maps Scheme, the relationship to the European flora, and hybrids were the main interests of members of the Society in 1957. Progress made during the year as demonstrated by the exhibits represents a sound contribution to knowledge.

J. E. LousLixy

1 Jurges, N. A., and Heywood, v. H., Nature, 179, 696 (1957).

\section{THE GEOGRAPHICAL ASSOCIATION}

T THE annual conference of the Geographical Association was held at the London School of Economics during December 31-January 3. Prof. P. W. Bryan, in his presidential address, fascinated and impressed a very large audience by a series of beautiful coloured photographs and his insistence that geographers must deal primarily with the land. scape as a whole, including the interrelated parts of the physical and the cultural. With the whole landscape as their basis, research workers could then go on to a detailed consideration of particular features.

One of these particular features, the landscape of glacial erosion, received detailed treatment by $\mathbf{M r}$. Vaughan Lewis, of Cambridge, in an analysis of the recent work done on "Erosion by Cirque and Valley Glaciers". He felt that the most helpful assumption now is that frost shatter is most severe in bergschrunds and related features, such as the enclosed head-wall gap reached by the upper tunnel dug through Vesl-Skautbreen, Jotunheimen, in 1951, when melt-water falls on to rock that is still a degree or so below the freezing point. This occurs in spring or early summer in the few weeks before the temperatures in the rock, and ice in the neighbourhood of the bergschrund, are raised to the freezing point.

$\mathrm{He}$ also considered that if rotation occurs as a result of the great downward thrust of an icefall, bed abrasion may be inereased locally, partly by this great downward pressure and probably more effectively by the higher velocity induced in the deeper lower layers of ice in contact with the bed. Ice has not sufficient strength to hold very small stones firmly enough to do much grinding and gouging of the much stronger rock, but if the boulders or blocks of rock are large, the ice can drag them past the rock with great force and produce correspondingly great erosion. If the rock is well jointed, this abrasion, coupled with frost shatter wherever low temperatures can reach the rock, may account for the bulk of glacial erosion. But if the rocks are massive and like granites and certain metamorphic rocks consolidated under great pressure, then joints may form near the surface-the primary ones lying parallel to the surface-as a result of the release of pressure on the removal of the overlying rocks. The rocks may burst upwards, as it were, an action which has been noted in certain New England quarries. This action may help the recession of the walls bounding valley glaciers. It is hoped that Mr. Lewis's findings may be published in full at 'a later date.

One aspect of the cultural landscape, namely, urban geography, received detailed treatment in several lectures and constituted the main theme of the conference. Prof. A. E. Smailes, of Queen Mary College, London, read a paper on "Urban Studies" and paid tribute to the pioneer work that had been done on spheres of urban influence and in many detailed studies of urban morphology. The latter, largely based on maps, had greatly added to our knowledge of towns, but sometimes the use of a two-dimensional map failed to convey the true character of an urban area. It could easily ignore what Prof. Smailes called 'the texture' of a town by failing to emphasize the three-dimensional aspect of buildings. With a wealth of illustrative matter and descriptive detail, he gave examples of various types of towns viewed in three dimensions and went on to an analysis of the main forms of urban growth in the past century. He distinguished, for example, with the aid of air photographs, the terrace ribbing pattern of much Victorian housing, the villa studding of more recent housing, and finally the block clumping of flats in modern times.

Prof. E. W. Gilbert, of Oxford, in a lecture on "English Seaside 'Towns", stated that roughly 2 t million people now lived permanently in these places. After describing their diverse origins and present functions, he discussed the many lines of research on them now proceeding in several universities. He made a special plea for more work on the medical 